\title{
Mutual Learning About Health System Performance in Australia's Intergovernmental Health Committee System?
}

\section{Crawford School Working Paper 1706 July 2017}

\author{
Amanda Smullen \\ Crawford School of Public Policy, The Australian National University
}

\section{Abstract}

Since the early 1990s Australia, through the Australian Health Minister's Advisory Council, began the process of developing a national health system performance framework. This includes service delivery measures for hospitals and has been used as a template for national data collections in mental health services. National performance frameworks have since become part of promoting greater integration of policy making and service delivery across Commonwealth and State jurisdictional health functions. The key focus of this paper is upon inter-governmental processes and routines to develop Australian national performance regimes in the realms of health and mental health care services. It presents initial findings from 26 elite interviews working across the inter-governmental interface, including some data about experiences of service managers.

The report provides two contributions to the existing literature on Australia's federal health system and more specifically health governance. Firstly, it presents a literature review of studies and theoretical concepts that have been deployed to examine cross jurisdictional processes of decision making. There is particular attention for the European literature on inter-governmental committee systems. Secondly, the paper presents initial findings from an explorative study of Australia's inter-governmental machinery in the realms of health and mental health care services. This explorative study was based upon an initial 26 elite interviews from respondents working (or having worked in) Australia's inter-governmental machinery, including some respondents from representatives of relevant Commonwealth semi-autonomous bodies. The researcher also observed two inter-governmental committee proceedings although reported data here draws only from interviews. These findings provide a first insight into the inner workings of Australia's inter-governmental health machinery. It is argued that there has been evidence of mutual learning from Australia's National Health Performance initiatives, and, exchanges and recommendations for future research to further investigate and pinpoint the causal processes through which mutual learning occurs are provided. 


\section{Suggested Citation:}

Smullen, A. (2017), Mutual learning about health system performance in Australia's intergovernmental health committee system?, Crawford School working paper 1706. Crawford School of Public Policy, The Australian National University.

\section{Address for Correspondence:}

Name: Amanda Smullen

Position: Senior Lecturer

Address: Building 132 Lennox Crossing Canberra

Tel: 0261258266

Email: Amanda.smullen@anu.edu.au

Crawford School of Public Policy

College of Asia and the Pacific

The Australian National University

Canberra ACT 0200 Australia

www.anu.edu.au

The Crawford School of Public Policy is the Australian National University's public policy school, serving and influencing Australia, Asia and the Pacific through advanced policy research, graduate and executive education, and policy impact. 


\title{
Mutual Learning About Health System Performance in Australia's Intergovernmental Health Committee System?
}

\begin{abstract}
:
Since the early 1990s Australia, through the Australian Health Minister's Advisory Council, began the process of developing a national health system performance framework. This includes service delivery measures for hospitals and has been used as a template for national data collections in mental health services. National performance frameworks have since become part of promoting greater integration of policy making and service delivery across Commonwealth and State jurisdictional health functions. The key focus of this paper is upon intergovernmental processes and routines to develop Australian national performance regimes in the realms of health and mental health care services. It presents initial findings from 26 elite interviews working across the intergovernmental interface, including some data about experiences of service managers.

The report provides two contributions to the existing literature on Australia's Federal health system and more specifically health governance. Firstly, it presents a literature review of studies and theoretical concepts that have been deployed to examine cross jurisdictional processes of decision making. There is particular attention for the European literature on inter-governmental committee systems. Secondly, the paper presents initial findings from an explorative study of Australia's intergovernmental machinery in the realms of health and mental health care services. This explorative study was based upon an initial 26 elite interviews from respondents working (or having worked in) Australia's intergovernmental machinery, including some respondents from representatives of relevant Commonwealth semiautonomous bodies. The researcher also observed two intergovernmental committee proceedings although reported data here draws only from interviews. These findings provide a first insight into the inner workings of Australia's intergovernmental health machinery. It is argued that there has been evidence of mutual learning from Australia's National Health Performance initiatives, and, exchanges and recommendations for future research to further investigate and pinpoint the causal processes through which mutual learning occurs are provided.
\end{abstract}

** An earlier version of this paper was presented at the Panel Welfare State Governance and professionalism panel, at the European Group of Public Administration Annual Conference, Utrecht 24-26 August, 2016.

Contact details:

Dr Amanda Smullen

Crawford School of Public Policy

Australian National University

Canberra, Australia

Amanda.smullen@anu.edu.au 


\subsection{Introduction}

Irreconcilable scholarly differences are apparent in (atomistic) economic accounts and (collective) sociological descriptions of the possibilities for mutual learning as a form of intergovernmental coordination (see Sabel 1993, Joerges \& Neyer 1997; Blom \& Brandsma 2009). Pragmatist thought presents a way out of this conundrum. Through recognizing both the individual and the collective, and the way in which their interaction recasts identity and meaning for both, pragmatist scholars suggest pathways for how habituation and trust can unfold in interaction, thereby enabling the evolution of ongoing mutual learning (Sabel 1993; Rogers 2009; Ansell 2011). Of course, the nature of learning may be manifold from instrumental and political learning to more reflexive and democratic social learning desired by classical pragmatists (Dewey 1927; Ansell \& Bartenburger 2016). This project aims to focus upon mutual learning among actors within the intergovernmental machinery. Mutual learning is defined as adjustment in actors' perceptions and beliefs about performance (and related changes in performance measurement systems and actions), rather than repetition or strategic presentation of learning. There remains only tenuous insights into the micro processes through which learning occurs and their interconnection with the macro system level of institutions and policy making (Gilardi \& Radelli 2012:161). Moreover, learning in Australia's intergovernmental system has not been systematically examined to date.

This paper follows the insights of both pragmatist scholars, and others, who identify trust as a precondition for the evolution of reflexive mutual learning (Gambetta 1988; Sabel 1993; Ansell \& Gash 2007). It seeks to extend this scholarship through a conceptual and empirical exploration of the micro processes through which mutual learning among Australian government health officials occurs or not. The focus is upon habituation, or rather the form, content, and processes of recurring routines about health system performance, and, the relationship of these with learning (Cohen 2007; Sabel 2006). Pragmatist scholars have argued that the formal and informal features of cross jurisdictional interaction can together contribute to trust building and thereby mutual learning. The significance of the relationship between formal interactions and the 
informal have been highlighted in literature describing cross jurisdictional interaction in the European Union and transnationally (Gehring \& Oberthur 2009, Sabel \& Zeitlin 2012; Gehring 2012). Formal and informal features of interaction pertain to the quality of dialogue in intergovernmental interactions, their structured character, the extent of face to face dialogue, fruitful conflict, and the development of commitment and shared understanding (Ansell \& Gash 2007; Ansell 2011; Gehring \& Kraphol 2007; Sabel \& Zeitlin 2010). Relatedly they include the relationship between formal agreements and informal beliefs and actions (Zurn \& Checkel 2005). Temporal aspects of interaction are also of significance to trust building and learning, including prior history of conflict and cooperation, related previous experiences of learning, and sequences of interaction within routines themselves (Sabel 1993; Ansell \& Gash 2007; Tavory \& Timmermans 2014).

This paper begins to examine the conceptual role of these features of cross jurisdictional interaction through a review of the literature. Furthermore, their relevance to Australian experiences are considered in light of initial empirical findings drawn from elite interviews of Australian Health Officials. More broadly, the report presents more general and descriptive findings about the inner workings of Australia's intergovernmental health machinery. It briefly compares these findings with the conceptual literature and makes recommendations for further research in this field.

The guiding exploratory questions for the report are:

(1) How has mutual learning been characterized in literature describing intergovernmental interactions and what features of interactions are meant to promote/inhibit learning?

(2) What characteristics of intergovernmental interaction - their form and content - can be observed in Australia's intergovernmental health system machinery?

(3) What are the procedural features of these routines that contribute to trust building and relatedly mutual learning? 
Australian intergovernmental interactions about health system performance is argued to be of both theoretical and empirical significance to both the policy learning and intergovernmental relations literature generally. Firstly, like Canada, Australia is a parliamentary federation with a somewhat chaotic history in the realm of health policy (and in general). The political oscillation from cooperative problem solving to antagonistic and strategic modes is widely recognized in accounts of Australian federalism. These suggest ongoing shifts in learning over time, yet we know relatively little about the nature and sequences of interactions or the internal machinations of these processes. Secondly, parliamentary federations such as Australia and Canada present interesting 'middle cases' of intergovernmental governance arrangements. That is in the sense that they are not as formally structured as the European Union or Germany, yet the ongoing existence of an intergovernmental committee machinery is clearly more structured than the 'selforganizing federalism' associated with the United State of America (see Gehring \& Krapohl 2007; Feiock \& Scholz 2010). The degrees of informality in Australia's nevertheless somewhat structured intergovernmental system are potentially conducive to routines of learning with selfdiscipline.

Thirdly, Australian experiences of intergovernmental relations remain a somewhat understudied realm, in part because of barriers to access (see however Botterill 2007; Fenna \& Phillimore 2015). The functioning of the committees of the Australian Health Minister's Advisory Council has hardly been studied at all, yet these have an extensive history of consensus decision making by virtue of the shared constitutional powers in Australian health policy. This contrasts with, and is an important counterweight to, the images and public displays of antagonism in Australian politics.

The report is divided into 8 sections. Firstly, some background into scholarly and practitioner motivations for examining mutual learning in parliamentary federations is presented. Secondly, in section 3.0 a more specific discussion of the arrangements for intergovernmental processes of advice and decision making in Australia's Federal Health System is presented. The focus of this study is primarily the Australian Health Minister's Advisory Council (AHMAC) and related national bodies that contribute to this process. Thirdly, in sections 4.0 and 5.0 an initial overview 
of conceptual accounts of types of learning and factors contributing and inhibiting learning is presented. There is a distinction made between the micro processes of routines and macro processes of adjustments in performance measurement systems and policy making for example. Fourthly, in section 6.0 the methods adopted for this pilot study and the process of interview data collection and analysis are described. Initial findings of the study are then presented in section 7.0 and related sub-sections, while discussion and recommendations for future research are presented in sections $8 \& 9$.

\subsection{Mutual learning and interrupted habits in parliamentary federations}

There is an established international scholarly literature examining the nature of interaction among policy officials in intergovernmental committee systems (Joerges \& Neyer 1997; BlomHansen \& Brandsma 2009; Painter 1998; Simeon \& Cameron 2002). A key focus has been to what extent is cooperation possible in situations of interdependency and through what mechanisms? Mutual learning enters into this focus as the most likely scenario for positive outcomes that are collectively accepted. Initially the literature tended to focus upon two standard perspectives in political science - strategic bargaining whereby 'interest based' assumptions characterize the postures of officials in committee interactions, or, coercion through the monopoly of central actors such as the EU commission or central government officials in federations (Joerges \& Neyer 1997; Painter 1998; Simeon \& Cameron 2002). In both instances the formal allocation of authority and rules of decision making are central to examining processes and outcomes of intergovernmental interaction. For example, constituent units can use formal decision making rules to prevent encroachment from the center, while the center can use their constitutional authority, agenda setting powers and budgetary rules to limit the scope of constituent unit discretion.

A third position has been to highlight a social constructivist vision whereby ongoing interaction between officials host informal dialogical processes that inform and change interests of participants. Such mutual learning perspectives posit that a problem solving orientation emerges through ongoing intergovernmental interaction. In the pioneering work of Joerges \& Neyer (1997), it was posed that 'supranational deliberationist ideals" emerged in the EU comitology 
system of the foodstuffs sector. Their claim is that formal intergovernmental committee arrangements host ongoing informal argumentative exchanges among (functionally equivalent) national policy experts. This enables the recognition of common shared perceptions of problems to form over time. Collective socialization among similar policy professionals is identified as the mechanism for common learning and relatedly cooperation (see also Checkel 2007).

In more recent studies, this position has been refined with other scholars identifying a more precise range of factors that may intervene in ongoing interaction and socialization processes. For example Gehring (2012) has argued and shown that both the formal features of committee structures and decision making processes, can work together with the informal, to foster productive cooperative exchanges; while Blom-Hanson \& Brandsma (2009) add that socializing shared problem solving depends upon the complex nature of the task being addressed. There has also been increasing attention between the relationship between formal agreements and the informal beliefs and behavior that actors undertake (Sabel \& Zeitlin 2012; Heims 2016). This is with the purpose of bringing into view the connect or disconnect between claimed (formal) commitment or adjustment and actual (informal) decision making and behavior.

While these contributions have enriched existing studies of the possibility for productive dialogue and adjustment through intergovernmental exchange, they fail to articulate the specific fine grained processes through which socialization occurs, the connections between micro encounters and evolution at the macro level, and relatedly, specifically reflexive mutual learning. In particular, it is often unclear whether socialization in interaction is predicted to occur through cognitive processes as suggested by rational choice theorists and some sociologists, or whether it is through habit and action as recognized by pragmatists This is significant since primacy to habit invites attention to intergovernmental interactions and routines as historical (Cohen 2007:777; Sabel 1993; Olson 2013). From this perspective the configuration and stability of interactions and experiences in the early years of intergovernmental relationships is conceived as creating capabilities for the future. It is not that cognition is irrelevant but rather that in the work of pragmatists it is habit that is the precursor and host of consequent cognitions and emotions (Cohen 2007:776). 
For research into intergovernmental interactions and their trajectories of cooperation, stalemate, or antagonism, this emphasis on habit invites closer assessment of rituals of interaction, as well as the sequences in adjustments of intersubjective meaning that these facilitate over time. In contrast to the automaticity associated with rituals as routines, pragmatists observe a much wider repertoire of action taking place in rituals as habits (see Sennett 2012:86-95; Camic 1986). These open up the possibility to be more precise about the sequences that enable cooperation to evolve or not, and the composition of formal and informal aspects of rituals in these processes. As Sabel (1993); Cohen (2006) and others have noted, routines can foster greater creativity than is attributed them by the image of unthinking automaticity, this is because it is through routine that novel situations come to be recognized (Camic 1986). Moreover, if working well routines are not frozen behavior but evolve and are 'living rituals' - "where the past continues alive in the present" (Sennett 2012:89).

The notion of 'living rituals' highlights both the collective macro element to routines that point to common histories and patterns in interaction, as well as the micro significance of these, where individual encounters are in themselves novel and, if become persistent, present the potential for informing changes at the macro level. It is in this sense that rituals and the social patterns they habituate become important to identifying micro processes of learning and adjustment. While cognition is part of this process, it is through habit that, among other things, background assumptions become solidified and that predictability in social interaction occurs (Misztal 1996:105). This enables trust in relationships to emerge although predictability itself has been criticized for disabling innovation and adjustment. Pragmatists argue however that it is possible for actors to be reflective of their habits and thereby direct them in cooperation with others towards ends that are collectively identified as desirable (Dewey 1927; Cohen 2007; Sabel 2012; Ansell 2011). The 'trick' is to subvert spirals of distrust through processes of interaction that enable (once antagonistic) participants to recognize their shared fate and productively cooperate. But the micro processes through which this happens, their feedback to policy performance and institutional system adjustment, and the empirical evidence of it remains scanty (see Gillardi \& Raedelli 2012:16; Jacobs \& Weaver 2015). 
Debates about the possibility of intergovernmental problem solving have tended to be eurocentric, thus ignoring experiences in other kinds of jurisdictions such as parliamentary federations. In contrast to the consensus tradition of many northern European countries, Anglo/French-Federations such as Australia and Canada have, at least from the outside, appeared to struggle with maintaining intergovernmental cooperation in a number of policy fields. Though in many ways more integrated than the European Union, the political historical records of these nation states suggest significant political volatility in the operations of their intergovernmental machinery. This can be attributed to both the adversarial and executive dominance influences of Westminster features in these systems, as well as their informality, which allows the government of the day to influence the form and regularity of interaction (Smullen 2014). In terms of analyzing processes of learning, these cases are of scholarly significance because of their higher degrees of informality, but also their apparent ongoing adjustment to changing political context. They present fertile cases for examining the role of habit over time, and its interruption, and the consequences of this for processes of interaction and mutual learning. Furthermore, they hold a somewhat middle ground to the self-organizing federalism attributed to the United States (see Feiock \& Scholz 2010).

Beyond the public political performance of acrimony, there have clearly been significant political and policy achievements obtained through Australia's intergovernmental system. For example, the National Competition Policy in particular has been cited as attaining a consensual problem solving orientation among officials that eventually brought about lasting adjustments to competition policy across the Australian Federation (Davis \& Silver 2015). Similarly, Australia has pursued a National Mental Health Policy since the 1990s which attained ongoing bipartisan and cross jurisdictional commitments to some shared financing and performance standards, and there has been ongoing work on a National Health Service performance framework since before that time. While of course these initiatives are hardly perfect, the fact of their ongoing evolution in the context of political change and some instability in the structures hosting intergovernmental interaction, invites further inquiry. In particular, a close up assessment of the nature and maintenance of routine and dialogue among Australian officials participating in the 
intergovernmental machinery is necessary to assessing and explaining mutual learning or not. This is relevant not only to scholarly debates about the nature of intergovernmental interactions and conditions of learning, but also to practitioner concerns about fragmentation in Australia's Federal health system and good health governance more generally.

\section{The case of the Australian Health Minister's Advisory Council and the development of National Health Performance Regimes}

The Australian Health Minister's Advisory Council (AHMAC) is an example of Australia's intergovernmental machinery and offers support to the Council of Australian Health Minister's. It provides strategic advice about the coordination of health policy and services across the nation, as well as operating as a national forum for planning, information sharing and innovation. AHMAC was preceded by an established tradition of Health Minister Conferences across state jurisdictions and related administrative official meetings already in earlier years of Australia's federation. The committees within AHMAC and indeed the structure of AHMAC itself presents an important example of functional coordination within Australia's federal health system. Members of this committee system include official policy experts from within health departments across the federation, as well as technocrats from within such bodies as the Australian Bureau of Statistics and Australian Health and Welfare Institute. There is a hierarchy to the committee system wherein departmental secretaries and ministers are found at the top level committees, supported by strategic and advisory committees at lower levels of the AHMAC machinery. The regularity of meetings of officials varies somewhat across committees, as will be described further below.

Before describing further the AHMAC committee system, it is important to first briefly locate AHMAC within Australia's federal health system. This is a complex mosaic wherein constitutionally prescribed authority for health policy and services no longer corresponds to fiscal clout. While the Australian Constitution, as originally proclaimed, limited the role of the Commonwealth (the national government) in health, leaving the former colonies - Australia's states and territories - primary responsibility for health policy and services, this has since 
changed dramatically. A range of high court decisions (relating to taxing powers, international treaties and financial grants), as well as the tumultuous introduction of both Commonwealth (federal) funded pharmaceutical benefit schemes (in 1950) and a universal health insurance scheme Medicare (first in 1975 as Medibank, then 1984), alongside a private health insurance system, has meant that the national government has become a key player in a highly complex and interdependent health policy field. This does not discount that "colonial and state governments had been funding and providing health services for well over 100 years" and through diverse health systems prior to a Commonwealth (read Federal) Department of Health even being formed (Anderson 2012:249; Gillespie 1991).

Figure 1. Overview AHMAC Committee System

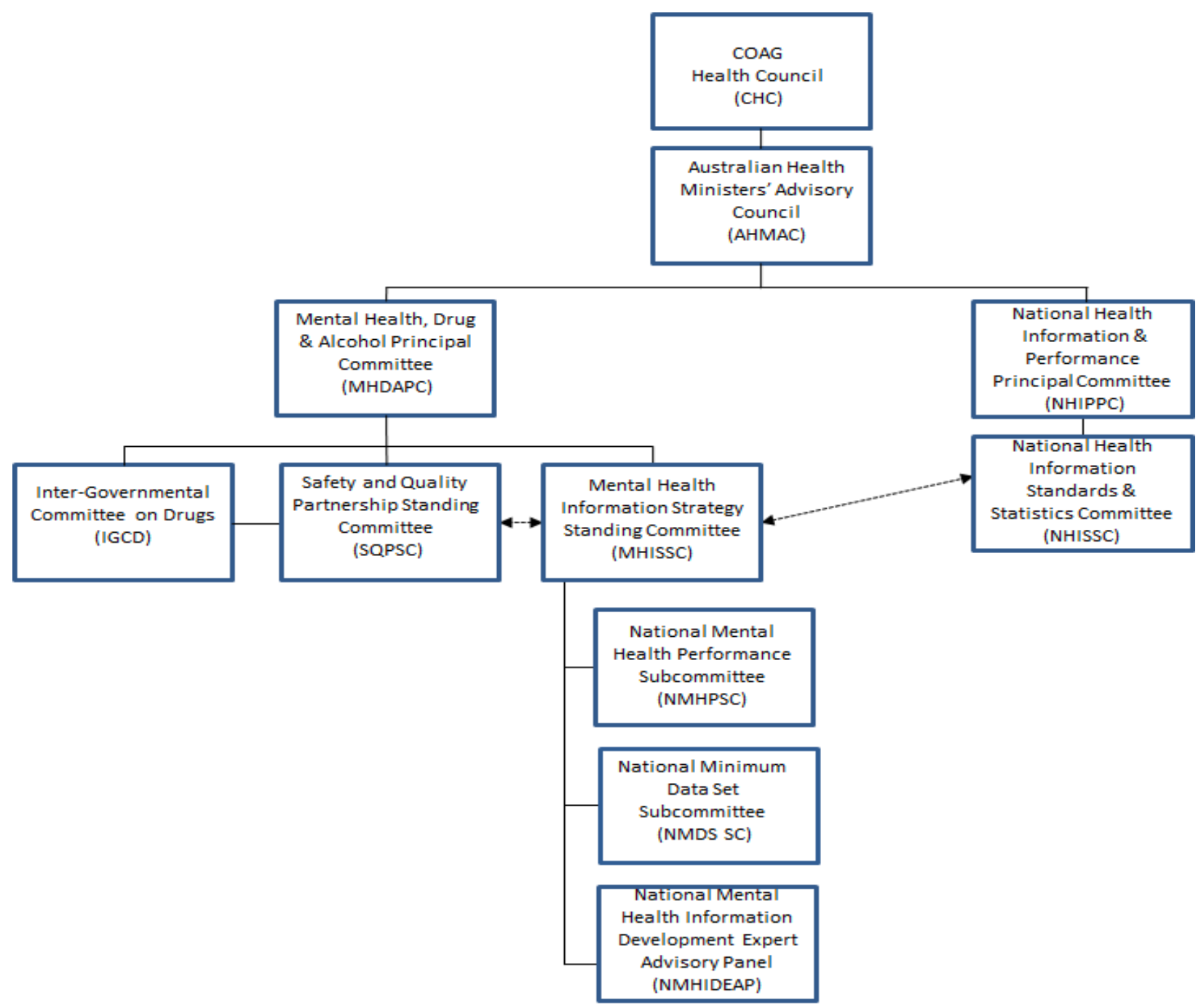


Intergovernmental health committees within AHMAC, and its' predecessors, have long played important roles as forums for coordinating Australian national health policy and health services within the context of interdependency. They are sites for informing, maintaining and overseeing national health and intergovernmental agreements. There are currently six principle committees, which are supported by a range of sub-committees. They include the National Health Information and Performance Principle Committee (NHIPPC), the Mental Health, Drug and Alcohol Principal Committee (MHDAPC), and the Hospitals Principal Committee (HPC). There are also executive and statutory agencies connected to, and sometimes represented on these intergovernmental committees. In 2012 for example a National Health Performance Authority was created as part of the then Labor Government's 2011 National Health Reform agreement and there are other bodies such as the Australian Commission on Safety and Quality in Healthcare, the Australian Health Practitioner Agency and the Australian Aged Care Quality Agency. Other key agencies represented and assisting the functioning of the committee system include the Australian Bureau of Statistics (ABS) and the Australian Health and Welfare Institute (AIHW). A recent diagram of the AHMAC committee system is presented in figure 1 above.

For the purpose of this study, interview respondents were identified primarily (though not only) from the National Mental Health Performance Sub-Committee (NMHPSC), the Mental Health Information Strategy Committee (MHISSC) and the National Health Information Standards and Statistics Committee (NHSSC). However, proceedings from the Safety and Quality Partnership Standing Committee (SQPSC) and the Australian Health Minister's Advisory Council were observed. Noteworthy is that there is some overlap in membership such that the interview respondents provide representation across almost all committees with the exception of the InterGovernmental Committee on Drugs (IGCD).

It is not unusual for committee members to have to function in the context of sudden changes in national health policy or intergovernmental health policy agreements following from new national (or even state) governments. This may include changes to formal committee structures 
or organizational units. At the same time, there is a surprising amount of continuity in the agendas of these committees as they oversee and lubricate more routine exchanges between jurisdictions. These include regular exchanges and decision making processes that take place outside of committee meetings.

\subsection{Theorizing mutual learning and related macro incremental change}

Ideally processes of mutual learning equate to an interactive and reflective process of inquiry into shared policy or performance problems, with related adjustments occurring in the perceptions and behavior of policy actors. This is one evaluative definition of policy learning as reflexive learning. It is consistent with pragmatic tradition and the notion that inquiries into policy problems and solutions are intelligent to the extent that they actively interrogate, through dialogue, what makes our policy beliefs true, and to evaluate (and eventually adjust) those beliefs (their 'warrantable assertability') according to their practical uses and consequences (see Smullen 2014). Recent work on experimentalist governance, and related scholarship on 'inquirement' in performance measurement, has sought to design flexible institutions that foster this inter-subjective orientation. However, it hardly needs saying that alternative, less alluring, experiences of learning populate the political administrative record (May 1992; Gillardi \& Raedelli 2012; Meyer \& Rowen 1977). Distinguishing these alternatives provides a useful heuristic for distinguishing specifically mutual reflexive learning from other types, and thereby interrogating the conditions and constraints to this type of learning.

While there are numerous renditions of types of learning in governance scholarship, the literature has tended to hover around four ideal categories (see Gillardi \& Raedelli 2012; Grin \& Loeber 2007; May 1992). I follow from the earlier work of May (1992) and his emphasis upon what is being learned. May (1992) identifies instrumental, political and social learning. Importantly for this examination of the relationship between habits as expressed in routines and learning trajectories, May's categories, such as instrumental and political learning share some commonality with sociological concerns for respectively myopia and decoupling of practices from symbols of performance (see Levinthal and March 1993). This decoupling presents limits 
to what is actually being learned and suggests that the presentation of performance for example may differ from practices of performance. For present purposes it is useful to have an overview of the types of learning identified in policy and governance scholarship (see also Ansell \& Bartenberger 2016). This enables developing a sharper definition of mutual learning to be used in later research.

The ideal types of learning identified in the literature include:

Experimental learning: the capacity to learn from exchanges about local (bottom up) innovation and problem solving through reflexive dialogue about means and ends, and adjustment in beliefs about their role in promoting better policy performance.

Instrumental learning: the updating of beliefs and techniques to improve policy performance through more effective means to given ends.

Political learning: the updating of strategic capacities to appear to improve policy performance whether through symbolically disconnecting external appearances of performance to internal techniques and practices or through political compromises about the framing of means and ends.

Social learning: the updating of the social construction of policy problems and ends to improve them that includes the lived experience of affected publics.

These descriptions comply broadly to other standard accounts in public policy and administration (Gillardi \& Radaelli 2012; May 1992). In recognition that experimental learning has sometimes been found to occur among elites with the exclusion of publics, it has been distinguished here from social learning. Nevertheless, it is also possible that features of these learning types may be found to occur together such as the possibility for democratic experimental learning (experimental and social learning). Furthermore, in an endeavor to identify and study trajectories in learning through intergovernmental interactions about performance, it may well be that experimental or social learning occurs only after other learning experiences and failures of policy performance (Bovens et al. 2001; Howlett 2012; Kay \& Boxall 2015). In their account of learning types, Gillardi \& Raedelli (2012:160) go further to propose examples of the micro- 
foundations that support these different types of learning at the organizational level. They include the transformation of actor interests and their socialization for (reflexive) experimental learning and the strategic pursuit of interests for political and instrumental learning.

Implicit in conceptual accounts of learning are inquiries about change, and specifically in the first instance, incremental change. Like learning itself, change too can take numerous forms as the work of Streek and Thelen (2005), among others, have identified. However, it is essential to distinguish between changes at the micro level of individuals and learning and the macro level of collective decision making and more broadly institutions. While Gillardi \& Raedelli (2012) focus upon the micro foundations of cognitive (socialization or strategic) changes, which may be the consequences of routines, Streek and Thelen's (2005) mechanisms are pointing to processes of macro/meso level institutional changes (though they also recognize these may follow micro processes). Both literatures, identify that a key distinction to make in the experience of learning and related change, is that between formal and informal adjustments. Significantly, the alignment and gaps between formal and informal institutions have been found to have important implications for the direction of learning and change. That is they conceived as part of causal mechanisms contributing to the possibility of reflexive mutual learning or not.

It is not entirely clear how the literature on types of learning and of incremental change might be connected. However, some initial suggestions can be posed. For example, experimentalist learning prides itself on seeking to overcome the distinctions or gaps between formal rules and informal practices that characterize effective operations at the front line. Incremental change through displacement or layering is argued to follow from ongoing dialogue between dispersed policy elites who contribute different contextual and informal knowledge about what works in their jurisdiction (see Piore \& Sabel 1984). Intergovernmental dialogue is meant to inform active inquiries into the informal production processes that characterize performance and enable actors, through initial adjustment in beliefs, to make suitable formal and informal adjustments to these practices. 
Alternatively, political learning presents the potential for significant gaps between formal rules and presentation of performance and informal practices. In this instance change occurs as drift, that is while there is the formal appearance of stability, informally other practices are being adopted to deal with changing contexts. In this instance informal adjustments are by definition not subject to dialogue between officials. This is because experimentalist governance suggests that processes of incremental institutional change can be directed through the active design of routines such that feedback about the informal would prevent change as drift. More broadly, experimentalist governance scholars indicate that when routines work to build trust among actors, they are more likely to present the conditions for authentic exchange about both the formal and informal practices of performance for example (Sabel 1994; Ansell 2011).

Trust, as the "mutual confidence that no party to an exchange will exploit the others vulnerability", appears as important mechanism in these learning and change processes (Sabel 1993). On the one hand, trust has been found to inform the degree of formality that characterizes institutional relationships and how interaction about performance should be governed (Stinchcombe 1986). On the other hand, trust between actors is also likely to affect the quality of dialogue between actors and their preparedness to authentically broach and recognize the challenges that improving performance presents. This includes the exchange of experiences with poor performance and the factors associated with it. As Sabel (1993) reminds us it is through trust that actors come to recognize and accept their interdependency and thereby address, among other things, the novelty that the informal presents for learning. Far from an easy trajectory, however, establishing trust often involves breaking down the barriers of mistrust and redefining the collective history that has informed it (Sabel 1992:1133; Gambetta 1988). Nevertheless, it has been found, though sporadically, to emerge in some of the most unlikely situations. A key pragmatist insight is that such trust can be forged through careful ongoing attention to the organization of habits and the interaction encompassed in these (Sabel 1992; Dehaven-Smith \& Jenne 2006; Ansell 2012; Sennett 2012).

A brief overview of the types of learning here presented, their relationships to mechanisms of incremental change, and relatedly, the relationships between the formal and informal that these 
mechanisms of change are associated with is presented in table 1. It is not argued that the rows per se pertain to given causal relationships, the table is for clarifying the concepts.

Table 1. Types of learning, cognitive mechanisms, change mechanism

\begin{tabular}{|c|c|c|c|}
\hline Type of learning & $\begin{array}{l}\text { Cognitive micro } \\
\text { mechanism..updating beliefs }\end{array}$ & $\begin{array}{l}\text { Potential meso } \\
\text { change mechanism }\end{array}$ & $\begin{array}{l}\text { Relationship } \\
\text { formal- informal }\end{array}$ \\
\hline Experimental & $\begin{array}{l}\text { Change of preferences - } \\
\text { based on peer inquiry. }\end{array}$ & $\begin{array}{l}\text { Displacement } \\
\text { Or Layering }\end{array}$ & $\begin{array}{l}\text { New knowledge } \\
\text { informal becomes } \\
\text { connected of formal } \\
\text { change. } \\
\text { Formal adjustments } \\
\text { made yet to be } \\
\text { connected to parts of } \\
\text { informal. }\end{array}$ \\
\hline Instrumental & $\begin{array}{l}\text { Change of preferences - to } \\
\text { satisfy short term needs. }\end{array}$ & $\begin{array}{l}\text { Layering } \\
\text { Drift }\end{array}$ & $\begin{array}{l}\text { Formal adjustments } \\
\text { made yet to be } \\
\text { connected to parts of } \\
\text { informal. } \\
\text { Formal adjustments } \\
\text { not connected to } \\
\text { informal. }\end{array}$ \\
\hline Political & $\begin{array}{l}\text { Strategic adaption to given } \\
\text { environment. }\end{array}$ & $\begin{array}{l}\text { Layering } \\
\text { Drift }\end{array}$ & $\begin{array}{l}\text { Formal adjustments } \\
\text { made yet to be } \\
\text { connected to parts of } \\
\text { informal. }\end{array}$ \\
\hline Social & $\begin{array}{l}\text { Change of preferences based } \\
\text { on changed social values, } \\
\text { bottom up social movements. }\end{array}$ & $\begin{array}{l}\text { Displacement } \\
\text { Conversion }\end{array}$ & $\begin{array}{l}\text { New knowledge } \\
\text { informal becomes } \\
\text { connected of formal } \\
\text { change. } \\
\text { Existing formal } \\
\text { arrangements used } \\
\text { for different purposes } \\
\text { to cohere with } \\
\text { informal. }\end{array}$ \\
\hline
\end{tabular}

*Adapted from Gillardi \& Raedelli 2012 


\subsection{Habituation and rituals as micro foundations for learning}

In identifying habit as action that can institutionalize 'living rituals' and foster eventual reflexive learning, pragmatists focus upon rituals as an opportunity to create meaningful communities. Many of their suggestions point to action that can improve the quality of dialogue and interaction. In contrast to sociological accounts of formal structure as myth and ceremony, the pragmatist position seeks to overcome the dualisms between formal and informal institutions (Meyer \& Rowan 1977; Ansell 2011:65-68). This is not to say that this is always successful and it is clear from the pragmatist literature that enlivening rituals through good habits requires concerted effort and discipline (see Camic 1986). It can however be the effort worth. As Sennett (2012) argues, it is through good rituals that the vulnerabilities of competition and cooperation, respectively a 'race to the bottom' and 'group think' can be brought in balance. He explains that good rituals can be preserved through repetition that is consciously refreshed; that transform objects such as goals of performance into symbols that direct us, and that are performed with the right emotion - for example emotions of seriousness, genuine concern or determination (Sennett 2012: 90-95). Conducted correctly, these features of ritual are meant to act to transform actor's pursuit of self-interest to those of the community, and at the same time, awaken empathy.

Similarly, Ansell (2011) has also identified features of interaction in rituals that are meant to create meaningful communities and overcome disconnects between formal and informal institutions. His prescriptions have been more specifically directed at addressing situations of interdependence and embedding this in ways that enables productive collaboration. They include (1) fruitful conflict through face-to-face dialogue (2) ongoing recursive problem solving, and (3) identifying quick wins. Like Sennett's notion of living rituals, these elements of collaboration are meant to foster learning and trust but most specifically through 'embedding interdependency'. Parties to exchanges are through the process of interacting both reinforcing material interdependencies but also consciously embedding their interdependence for collective advantage. This is what is meant by the Durkheimian reference to the whole being greater than its' parts. A further attribute of positive, reflective interaction, has been identified as the plurality of knowledge incorporated in dialogue (Sabel \& Zeitlin 2010; Bohman 2010). Plurality can be 
assured through the incorporation of distributed knowledge from different scales in a political system, as well as the range of actors incorporated in dialogue. More specifically De Burca (2010a; 2010b) has argued that the incorporation of a plurality of knowledge from bottom up movements affected by given policies can aid elite learning. Though she also recognizes a positive role for stable membership among elites sharing knowledge.

Of course, there are features of rituals and interaction that can disrupt the promotion of fruitful dialogue and relatedly trust. These include instability in membership of ongoing procedures or failure to genuinely engage in dialogue such as concealing information about performance, using information for purposes other than reflective learning, or lack of fruitful dialogue and possibility to interrogate information constructively. These attributes pertain to the failure to ingrain disciplined habits in rituals of interaction and relatedly establish appropriate balance between the formal and informal attributes of interaction. Against the background of these literatures of learning, change and rituals, an initial exploration of the evolution of Australian health system performance measures were undertaken.

Table 2. Micro-features of interaction and relationship to mutual (experimental/social) learning

\begin{tabular}{|c|c|c|c|}
\hline Author & $\begin{array}{l}\text { Concepts (micro } \\
\text { components mechanism) }\end{array}$ & $\begin{array}{l}\text { Relationship mutual } \\
\text { learning }\end{array}$ & Dangers/barriers \\
\hline Sennett & $\begin{array}{l}\text { Repetition, Symbolic } \\
\text { transformation, Right } \\
\text { emotion }\end{array}$ & + & Remains symbolic \\
\hline Ansell & $\begin{array}{l}\text { Fruitful conflict through face } \\
\text { to face dialogue }\end{array}$ & + & $\begin{array}{l}\text { No fruitful conflict, stuck by } \\
\text { institutional veto players. }\end{array}$ \\
\hline Sabel \& Zeitlin, De Burca & $\begin{array}{l}\text { Plurality of knowledge - } \\
\text { such as including affected } \\
\text { publics. } \\
\text { Stable membership - thus } \\
\text { ongoing interaction }\end{array}$ & + & $\begin{array}{l}\text { No plurality of knowledge. } \\
\text { No quality exchange } \\
\text { between different sources of } \\
\text { knowledge - concealing } \\
\text { information. } \\
\text { Instable membership }\end{array}$ \\
\hline
\end{tabular}


An overview of the different concepts or rather factors presented here and their posed positive or negative relationships with mutual learning is presented in table 2. Noteworthy is that these factors are posed as the micro processes through processes of socialization occur, including socialization to strategic interaction.

\subsection{Investigating Australian health intergovernmental committees and the evolution of health system performance regimes: methods}

There is a long tradition of intergovernmental exchange about health policy in Australia's federal system. The historical legacy of states, or rather distinct former colonies, as sovereign entities in both policy and service provision of health gave leverage to these constituent units in their exchanges with the more recently formed Commonwealth (federal) government. While the Commonwealth has repeatedly attempted to assert policy direction in the health field, and thereby feed a legacy of distrust, particularly in the realm of hospital services, the states remain formidable entities antagonistic to national encroachment (see Gillespie 1991). In contrast to the adversarial exchanges prominent in depictions of Australia's Westminster institutions, consensus decision-making has sometimes flourished in intergovernmental exchanges, particularly in health where conditions of polyarchy prevail (Painter 1991; Botterill 2007; Davis \& Stivers 2015). Yet empirical research into the functioning of such committees is limited, in part because of barriers to access for researchers. For example the actual members of committees, the agendas and minutes of meetings, their consultation with external actors, as well as the regularity of meetings are generally not available publically. The public availability of intergovernmental committee information varies across policy fields and is penetrable for researchers but requires much time, effort and contacts.

Secrecy in Australia's intergovernmental field is associated with traditions of executive federalism that draw similarities between the intergovernmental arena and the secrecy of cabinet. Even though Australia is one country, notions of constituent sovereignty inform understandings of the intergovernmental sphere and its operation. This study is among the first Australian 
investigation of intergovernmental committees in health, and certainly the first to compare across health intergovernmental committees. The focus here is upon National Health Information and Performance Principle committee and related sub-committees, as well as the National Mental Health, Drug and Alcohol Principle Committee and it's sub-committees. Both of these committees officially play advisory roles in the formulation of national performance measurement regimes. They are subsumed in a hierarchy of committees with the council of Health ministers across all jurisdictions at the pinnacle (see figure 1 above). Significantly, the committees examined here are composed of public servants with fairly permanent tenures and do not include the committees wherein secretaries of department (with less permanent tenure) participate. Furthermore, public officials from expert bodies working on the interface of Australia's Federal system were also incorporated in this study eg. ABS, AIHW, NMHC, NHPA. This is because actors in these bodies are represented on intergovernmental committees but also play important ongoing roles in the collection and exchange of performance information. Indeed, the AIHW acts as a secretariat for a number of the intergovernmental committees here examined.

While the investigation focuses somewhat statically upon the characteristics of intergovernmental interaction and their form and content on these committees, it is conducted against the background of the evolution of national performance frameworks. Since the mid1980s and early 1990s, intergovernmental committees in health began to develop national performance regimes in respectively health policy and services, and, mental health policy and services. This occurred alongside developments in health performance regimes at the state level. While initially the creation of national performance regimes were primarily motivated by a desire for comparative reporting and benchmarking in somatic care, and as a driver for improving data collections in mental health care; increasingly the measurement systems have been seen as instrumental to promoting greater integration across services that are the responsibility of different jurisdictions.

Perhaps surprisingly, given Australia's reputation as among 'leaders in NPM', the growth of health service and management performance measurement systems has tended to lag behind other Anglo Saxon countries such as England and Canada, or indeed European countries such as 
The Netherlands. Instead, Australia invested more in population health data as opposed to performance management measures of services. One explanation for this has been fragmentation, which is related both to Australia's federal health system and specializations within health. The analysis of intergovernmental routines here occurs with the knowledge that Australian national performance regimes in health, hospital and mental health services have grown quantitatively in terms of numbers of measures collected and in their density, the detail and number of measures collected for particular outputs. In the case of mental health, there have also been actual changes in how performance itself is conceived in regime design. There has been a shift from more narrow input and output measures of services to a broader more outcome recovery orientation. The recognition of interdependencies across policy sectors and jurisdictional mandates has more clearly been incorporated in development plans for national mental health performance regimes than in regimes for health services. (This raises further questions as to why there are differences and whether this relates to routines of interaction?)

In order to investigate the characteristics of intergovernmental interaction within Australia's intergovernmental health machinery, an initial exploratory study was conducted. This included identifying existing committees, their membership and where possible history and any committee publications. It was initially difficult to identify committee members as the secretariat responsible for these committees would not provide actual names of representatives nor a register of how membership had changed over time. It has since become apparent that they do have this information, including minutes of all meetings and regularity of meetings. Some of the committees had published reports, particularly on the development of national performance regimes, and these provided important initial sources for identifying past and present committee members. Furthermore, an initial chronology of developments in the National Health Performance systems was created, together with relevant published documents and changes in national governments and reform intentions. This is currently being supplemented by assessments of performance regime development in 3 of the 8 state/territory jurisdictions in Australia. 
As there was very little published information on the functioning of the intergovernmental system, it was necessary to begin exploration of national performance regime development and related intergovernmental interaction through interviews. An initial list of the names of members of the relevant committees was made on the basis of published reports. This led to a small pool of 12 people who constituted potential interview respondents. Some of these respondents' names were from the committee's operations in earlier periods, as well as committee members in the present time. The members of committees came from state and Commonwealth jurisdictions, as well as from New Zealand (who has standing membership on most intergovernmental committees in Australia,) and other professional and service providers bodies such as peak NGO bodies in healthcare and mental healthcare and private insurers.

The next step was to develop a semi-structured interview schedule that inquired into the form, content and processes of intergovernmental interaction. The questions were developed using concepts from pragmatism, interest based approaches and the logic of appropriateness in intergovernmental exchanges. There were questions pertaining to the structure and form of intergovernmental exchanges and rituals, including their degrees of formality and informality, the contacts that committee members had outside of the formal committee meetings, the nature of dialogue within committee meetings and types of conflicts and procedures for resolution. Furthermore questions pertaining to types of learning and feedback about health system performance were incorporated in the interview schedule. Three different interview schedules were developed for different kinds of actors involved in intergovernmental exchanges. These include an interview schedule for Commonwealth representatives and bodies such as from the Commonwealth health department and Commonwealth agencies, an interview schedule for state officials overseeing state health systems, and contributing to state health policy making and an interview schedule for managers within health services at state level. The inclusion of state health service managers among respondents was for investigating the uses of national performance measures at the local level, and vice versa eg. the role of bottom up learning from states to the national level and the relationship between formal agreement to performance measures and informal action. 
Finally a snowball approach for identifying respondents was adopted from the initial rounds of interviews. An initial round of 26 interviews were conducted in the period October 2015 December 2016, the findings of which have been used for this report. The interviews also presented the opportunity to collect a range of publications relating performance measurement regimes at both the national and state level including annual reports, internal performance documents and documents relating to the collection of performance data more broadly. The interviews required a commitment to anonymity often both of the respondent and the state they represented. None of the interviews were audio recorded, in order to promote openness in the exchange, and the responses were all transcribed by the lead-researcher. The transcription included documenting direct quotes from the respondents as well as a summary of their responses to the questions. The data was coded, together with research assistants, using NVIVO. This coding initially drew from pragmatist theories but included identifying more general themes that became apparent across the interviews. There has since also been an opportunity to observe two intergovernmental committee proceedings but then on the proviso that no documents be taken from the meeting or directly reported on. It was possible to interview participants of intergovernmental committees on the basis of what was observed and then report on that.

\subsection{Initial exploratory findings about routines and learning through Australia's intergovernmental health system}

Despite the ongoing nature of this research, it is nevertheless possible to report some selected evidence from the study. In order to do this systematically, it is here presented according to the initial questions posed in this paper which of themselves relate to the conceptualization of 'living rituals', the characteristics of these processes which build trust, and their contribution to the attainment of mutual learning among officials. Following from the previous conceptual discussion, the first question guiding the presentation of findings relates to stability of membership, regularity and structure of meetings, the formality and informality that characterizes intergovernmental committee interactions, the nature of interaction eg. strategic, deliberative, recognition of interdependence, and the substantive content of exchanges. The question was: 
What characteristics of intergovernmental interaction - their form and content - can be observed in Australia's intergovernmental health system machinery?

\subsection{Membership and structure}

A first observation that became quickly apparent in the process of interviewing participants of Australia's intergovernmental health machinery, is that these representatives, particularly at state/territory level, are composed of a relatively small and stable group of policy and administrative actors. It was not uncommon to speak with respondents who acted as representatives on a number of intergovernmental health committees. Furthermore, more than half of the respondents had been active on intergovernmental forums for long periods of time eg. in excess of 5 years, and in many cases in excess of 10 years. There were at least 3 respondents who had been working on intergovernmental committees for almost 20 years or even more. This indicates, that at least at state government level, there were high degrees of stability among committee members. A typical description of this stability was as follows:

It is correct to say that there is a small number of officials working in health across the different jurisdictions. It's common to meet the same people on national committees. For example I was on 2 committees at one time and kept coming across the same people particularly from smaller states like state X. (InT\#1).

Furthermore, the committee members often had other associations with one another as a consequence of their profession, particularly if they were psychiatrists or from other medical professions. This finding is somewhat dependent upon the level within the committee system wherein respondents were from. For example since the top layer of the committee hierarchy included politically appointed bureaucrats, their ongoing membership on inter-governmental committees was vulnerable to political turnover. 
By contrast, and as is discussed further below, the Commonwealth representatives on intergovernmental committees, particularly the lower level committees, were more variable and often short lived. One respondent expressed this as follows:

The Commonwealth presence on the committee and contacts for state officials was fairly static (in the past eg. early 90s AS) however more recently it has been a revolving door. Their presence is missing there is not enough consistency to make a real connection. (InT\#7).

Another respondent was more precise in their description stating:

Commonwealth person on the committee changes regularly, that is often with the government and machinery of government changes. We've had around 8 different Commonwealth members over the 15 years I've been involved. (InT\#4)

This respondent added:

Initially, with the start of the national mental health strategy, we did have a mental health unit within the Commonwealth health department that acted as a secretariat. This meant a more continuous point of contact in the health department for the committee. About 7 years ago they abolished these mental health positions in the Commonwealth which decreased the capacity of the secretariat (InT 4).

It should be noted further that the committees and sub-committees here examined met from 3-6 times a year for approximately 2 days per meeting. However, all respondents indicated that they had contacts outside of the formal meetings. These contacts included out of session decisionmaking or related to committee work.

In terms of the structure of intergovernmental meetings themselves, it became apparent that the meetings tend to be highly structured events, with repetitive formalities and designs. For 
example, the committee meetings are preceded by a clear agenda that is circulated to members some weeks in advance. These agendas are often self-perpetuating in that many items are ongoing for long periods of time. As one Chair of a committee explained:

The committee has a mechanical time-table that keeps the members on their toes and to consistent definitions. ....most of the time on the committee is spent managing the process to get agreement on how to measure something and then getting them all to measure it consistently. (InT6)

Of course these national systems are in general slow methodical working through. (InT\#6). Another respondent explained:

The committee has proper business rules and our work plan must be approved by X (higher level committee).

A somewhat less complimentary description was given by another respondent:

Committee X...is bureaucrats on steroids. If 1-2 jurisdictions have a problem, a particular proposal will never go anywhere. (InT\#14)

Of course, it (a decision) has to go up the committee structure and final authority is with the ministers who can knock off anything. (InT\#14)

\subsection{The formal and informal}

The apparent formality of the hierarchical structure of the intergovernmental committee system in health and their agenda and programs was complemented by high degrees of informality. This was particularly apparent in the ongoing contacts between committee members outside of the formal processes of meetings and decision-making. Informality and bottom up initiatives were also evident in the way in which national mandatory performance data sets evolve. Some indications of the informality that supports ongoing formal intergovernmental interactions are illuminated in the following responses: 
We do also look to other jurisdictions as to how they are collecting data and how they feed this back to their operational people/hospitals. We had someone meeting with an X official.,.. and we are also talking to (another jurisdiction_) on this...(InT\#1)

Person X knows everything in terms of inputs, outputs and outcomes. If I ever have a question about numbers I just call X. (InT\#4)

The good part about networking is that we do share information and data and that's useful...there are a lot of relationships that are formed and maintained. (InT\#14)

There is a sense of cohesion and willingness to engage on the committee and they do a fair amount of out of session work. It is a helpful networking experience, getting to know peers in other jurisdictions, people you can ring or contact regarding particular problems. (Int 11)

If $X$ receive data they find weird, they typically call the appropriate official in given state/territory to query/clarify. They seek to maintain good relationships and there is a general interest across jurisdictions to have comparability and good quality data/data sharing. (Int 16).

With regard to references to the role of informality in enabling the design and evolution of performance measurement systems, this was expressed as follows:

There are plenty of examples of collaborative efforts across states/territories as a consequence of being on committees and this has increased over the last 5 years. It used to the be case that the national committees were to serve the national data set and getting that to work but the 
states/territories have richer data and it's been possible to pool that data together at times for our own initiatives. (Int 3).

Besides the contribution of the informal in supporting qualitative relationships of the committee and their exchanges of data, there were also references to informal practices that subverted some of the intended goals of the national performance measurement systems. These were sometimes explained with references to the inadequacies of performance measures, but also by strategic interaction and relatedly inability to agree on performance data collections.

Some things just can't be measured easily. For example measure $X$ - this has a national interest but there is no mechanism to report on it. (Int 3).

One area where this is currently the case is with respect to differences in $X$ data. It varies because the way the data is sourced is different, but also because there maybe different legislative requirements as to which data must be collected (int 14).

With regards to political constraints on members of committees, this is faced more in the states/territories themselves. The people involved in data and on the data committees generally want to see their data used and reported but of course they may face different sensitivities in their home state. It is not uncommon that representatives on committees agree to share data for purposes of given items but that they require approval with regard to whether that information is publicly released (int 14).

The national performance framework doesn't marry well with other national performance measures for mental health, for example the AMHOCN outcome data (for clinical routines, $A S)$. They have kept health and mental health separate in this. They have had benchmarking projects in AMHOCN but they are not required to work together with the national service indicators and this creates fragmentation with each other at Commonwealth level (Int 13).

There is a long history of collecting data but it is only recently that it has started to be used. It's indicative that the data hasn't been used when only now there is a realization that the data is not usable or that the quality is poor - this is a strong proxy for indicating that the data has not been used. At the same time, by virtue of using the data it will become better quality data (Int 13). 
There was also reticence to publish, it is of course a political process. At the time the measures were set up there was the view that the states can't be trusted to run the health system properly. There were outcomes in the agreement eg. PBI-9 type II diabetes - it is not set up in a way that it can't be duplicated. There was also the Straph measure which is quite silly because all the jurisdictions can measure this and its' easy to meet at a hospital level. (Int 10).

$X$ had proposed 27 indicators where 16 of these could not yet be reported on. There was no agreement at national level what the reporting should be. (Int 13)

Whenever one jurisdiction can't report, we make it voluntary reporting where that jurisdiction can withhold their information. But it can also be that the figures are too low eg. the data not reliable, then we may not report. For example NT, ACT and Tasmania can have poor quality data because not representative data (Int 4).

Finally some respondents also indicated informal ways in which they sought to satisfy the measures that were not always apparent from the reported data. For example:

We don't tend to use it in my operations. It has meant that I've had ministers on my back and the media does also watch it. If they give a bad report-I usually know it can be in the analysis. When in $X$ we had robust debates with AIHW-about the role of context and what the data then means. (Int 10)

Other respondents discussed practices that they knew had been adopted to ensuring attaining good performance, such as exchanging knowledge across jurisdictions around patient flows for emergency waiting times or contacting private providers.

\subsection{The nature of interaction on the intergovernmental committees}

In general respondents identified a highly consensual decision making environment on the intergovernmental committees examined. While there were of course disagreements identified, these were arguably structured in ways that allowed a deliberative interrogation of problems to be pursued as opposed to primarily strategic interaction. Furthermore, there were examples of 'fruitful conflict' identified that were claimed by respondents to promote positive forms of 
learning. However, the nature of the committee structure meant that interventions from higher levels or from political superiors at state level could prevent further implementation of learning insights. Some examples of references to the nature of interaction on committees are provided below:

The deliberations are collegial though very detailed. Members are most likely to say to one another we don't understand the differences between your numbers and ours rather than attack the quality of someone's data (InT 16)

We did have robust discussions and I was committed to ensuring deliberation. It was difficult when one jurisdiction held a strong view that others don't hold (InT\#4).

Recently the $X$ committee has been looking at $X$ data. One jurisdiction has been presenting and discussing on what we classify with respect to $X$. These kinds of presentations do have an impact on potential future directions (Int 14).

The atmosphere on intergovernmental committees is very collegial. The states/territories officials do share their experiences of problems in the healthcare field. There are usually some points of difference though (Int 1).

The discussions are quite robust. People are honest and fairly brutal about their own systems. For example I mentioned that study $X$, it demonstrated .... These discussions can be like here's our dirty laundry. The NGO rep on our committee is very plain spoken and direct - he says you've been talking about that matter for 2 years now, why don't you do more about it (Int 14).

One respondent did however remark,

"Committees are very slow to make decisions... it has consensus based decision making process but nothing can happen without the Commonwealth's support" (InT \#3).

Similarly another respondent offered the proviso that 
I guess it's true to say in Australia that though it is a small network of officials across jurisdictions that often know each other through committees, we still keep our cards close to our chest (InT\#1).

With regards to the input of lay publics to the committee processes and more broadly understandings of performance, the mental health respondents had the most to say.

They get guided a lot by what consumers think. Lots of stuff is feedback from patient experience. Experience in mental health is a big determinate of your outcome. Experience of people reports. Most states collect a satisfaction tool - a stratified sample, NSW have a different version. They have all agreed on common standard the YES (your experience of service) (Int 21).

Wouldn't have been able to do recovery output without patients - Ifeel sorry for other committees without those patients. They are not challenged no one is aware of problem. Attitude of health system to consumers, and consumers themselves are often very ambivalent. It's a dependent relationship - can't be too critical of your doctor. Patients have not felt empowered to question. In mental health patients aer empowered and have right to question. There are lots of fantastic doctors that do have good relationships - on individual level not systematized. You have to stop and listen to what they have to say to you (Int 21).

There is a lot of development work going on. For example real changes are happening like linking the MBS and PBS data sets with census data. An ABS rep has presented this at one of our workshops. X (representing consumers and carers $-A S$ ) has been part of pushing for data linkage with the population and this has the potential to change our understandings of what we are doing and how we can plan strategically. These linkage efforts were really created through malcontent, it was a consequence of the squeaky wheel, so the inclusion of these alternative views are driving innovation and new avenues of inquiry (Int 19)

One of the issues that seemed to introduce more strategic behavior into the committee proceedings included discussions over the definition of national performance measures and also the public release and comparative reporting of this information. Furthermore, changes of government did interfere with cross jurisdictional interaction. Some examples from the respondents about these issues include: 
With the coming of the Rudd government and COAG changes Premiers became more involved in negotiations and it changed the risk profile with health. Now the Premier signs off on agreements but Treasury receives the funding. Then the department of health has to begin begging for our money from the agreement. With the National Partnership Agreements we don't get the money until we have met the targets in the agreement. The idea is that since Treasury bears the risk that we may not meet the targets then they are able to manage the financial side of our health costs (Int\#6).

This respondent explained that these changes, in combination with the increasing number of National Partnership Agreements, meant that work was transformed into just trying to oversee the most risk-full agreements and measures. This was because it became impossible to oversee all the data that was being requested.

Similarly, another respondent explained how political changes sometimes had the consequence that impassioned policy actors in the intergovernmental sphere were left stranded with promises and initiatives that were not being honored. This had the consequence of undermining their commitment to future initiatives around health system performance.

The bureaucrat has been uncertain of government's position and uncertain financing. They are moved around a lot. And then when something comes along - and they want to own it, they don't own it. So whenever a policy issue comes along the public servants are hamstrung (inT 21).

State representatives are however very wary of these circumstances and will sometimes collectively act to repay experiences of being neglected by the Commonwealth. This was expressed in relation to a new policy initiative around performance measures that was received with caution by the States:

They wanted to make it a bigger report - they all pretty early on decided not to agree. In the end they did agree that some data (be shared from Commonwealth). AHMAC decided not to share 
information. At MDAPSI level states decided not to share information. If it had been a different moment in time. At time of $X$ funding. They felt justified not revealing things (relationship issue) (Int 21).

You know a lot about their data but don't have spreadsheets. We can do a lot of comparisons it's quite detailed to know what everyone is doing. Know how they spend, their averages. What you don't see is point to point variations. The dollars are not equally spread. You don't see their best and worst (Int 21).

In the realm of hospital performance in particular, there were also references to not sharing data. Such responses included:

It was always a problem to subordinate performance within a financial agreement. If the agreement is no longer there then it's pretty difficult to get cooperation with collecting the performance measures (Int 12).

Or

With $X$ they had trouble because the states were not giving data anyway, it is difficult to come up with a common measure that is not bad from the point of view of anyone. Or where the common denominator is that it looks badfor everyone (Int 12).

There were also numerous references to the bigger states and how their relationship with the Commonwealth or with each other, sometimes interfered with otherwise good initiatives.

Some disagreements among jurisdictions also had to do with personalities. Victoria and the Commonwealth used to often fight. And the Vic representatives were often at loggerheads with $X$ (the data person) even though he was Victorian. 
Other themes that came up in describing intergovernmental interactions included conflicts between particular states over certain performance issues, but also the role of developing consensus about certain themes. In particular the mental health committees offered examples of close exchange over sensitive topics such as separation and involuntary restraint. This has seen important developments in the sharing and public provision of sensitive data. Furthermore, the respondents from the mental health committees identified the important role of lay representatives in changing the dynamics in dialogue about performance measures. For example:

There is quite a blurred line between the technical aspects of our discussion and advocacy. When choosing indicators to measure for example the carer/consumer reps argue for certain measures because they are important not because they are measurable. Consumer/carer reps provide a huge contribution. Also because data development is slow and requires significant time and attention, consumer/carers are good at keeping us thinking about broader issues such as recovery and bigger social issues that affect mental health (Int 22).

There was also some expression/acknowledgement of interdependence across jurisdictions and references in changes to decision making processes because of this. For example,

If you don't have single funders, you don't have a single person that can make up their minds. Consensus decision making has changed over the last 4-5 years. We did have majority decision making but if you didn't support the reporting then you weren't bound by it. Ideally you want all the data make the benchmarks because it effects the reliability of the data. If NSW doesn't take part then there goes $30 \%$ of the population and your benchmark. It is very interdependent in that way (Int 3).

This respondent later went on to explain:

$X$ has no way to force jurisdictions to provide consistent data. AHMAC tries to encourage it but it has to be worked through in the process in order for it to happen. Consensus is really the only 
way. Sometimes there is external levers like money on the table. This does actually work. It's either bribery or win jurisdictions over by the dint of argument which is a much slower process. There is also an under estimation of the work involved in bringing changes about (Int 3)

Within the realm of hospital performance in particular there were a number of references to the political sensitivity and strategizing in the process. For example:

The process of performance measurement often involves many stakeholders in a political realm. With the National Emergency Access Time (NEAT) and National Elective Surgery Times (NEST) it was the ministers that decided these would be important. They asked a Senior Clinical Advisory group with $X$. There were 4-5 clinicians assembled and they went around and consulted what would be the appropriate measures but the ministers have picked these measures. COAG process involved clinicians lobbying about what should be written into the agreements for example the National Partnership Agreement (Int 11).

Another respondent advised on these particular measures:

Inevitably notion of reward payments brings gaming into the system. With regard to the NEAT- the emergency medical specialists did a good job in convincing everyone that it is important (Int 10).

There is the admitted NEAT which is low mid $40 \%$ and then the non-admitted NEAT which was at about $90 \%$. With regard to the admitted NEAT, everything depended on the relationship with the external community, not the internal pathways. There is a lot of danger in a metric that does not affect the system (Int 10).

With regard to the NEST-electives, they get bumped because of emergency department demands. This means you need to think about Who waits for what, where and why? The information required is then more system wide. The volume in demand outweighs capacity. The NEAT -can interfere with NEST... Some of the strategies that have been used for improving patient flows have including creating medi-hotels - it's an apartment block near the hospital where people can recover from surgery for example (Int 10). 
A similar theme came up about money and the effect of finance upon the willingness to supply data in the realm of mental health services. In this instance it concerned the way that such incentives directed attention away from other service needs.

Also the ABF for example will soon include financial consequences if it is not supplied on time and compliant to certain form. The creates the energy in states/territories to ensure that they are complying to ABF requirements. Such initiatives stall development elsewhere, for example it's stalling development of our living in the community questionnaire. This is in development and such a critical policy questionnaire but the measures are just sitting there, ready to go, but everyone is busy with ABF (Int14).

\subsection{Trust and learning over time}

The respondents reflected on numerous occasions about the experience of learning and trust with respect to the development and exchanges about performance measures over time. These included references to formal procedures for publicizing performance measures and the political consequences or interventions following from these.

We do receive an embargo copy of the $X$ reports about a week before they are publically released and we find that useful. It gives us time to brief the Minister and prepare them for questions/reporting from the media for example. In X poorly performing ED departments are front page news. It receives a lot of hype but then for a short amount of time (Int 1).

There was also an incident of a politician coming to a health service provider without notifying the Director beforehand. The Director's experience was summarized as follows: After the call, the respondent advised that this kind of situation was the consequence of an accidental government that just didn't know the rules of appropriate behavior. Nevertheless, he advised that he relies heavily upon the State Department of health for some stability (Int 10)

Finally some references to developing trust over time: 
we moved them from being nervous about details to becoming more strategic about sharing deidentified preliminary results to ensure that our methods were right and that there were no anomalies with data .... Once they got into details, started to understand it. Committee X has been really helpful in coming to see whether there are systematic differences in how their jurisdiction collects codes or data.

What started out as hostile reservations that developed into trust over time. There was some initial level of reserve but once states realized that we were seriously independent and highly skilled at doing what we do - they came to accept the authority of the organization.

There is more recognition that hospital care is expensive and that it is better for everyone to keep people out of hospital. If successful, such a view will see fewer people coming to hospital and will meant that more people are putting their demands on primary care. This puts the costs on the Commonwealth (Int 10).

We pick up the health round table data and if some hospital is performing incredibly well, we just ring them. It happens all the time. I have informal contacts X. There are also more formal approaches for example where sharing of data occurs following a formal request - we approach hospital management for example about their theatre throughput - then you might formally ask and write a request to do a comparison. This happens a lot in the public system. The private system and the public system are apples and oranges.

We made it clear that publication of benchmarking part of improvement-for majority it could show improvement - they had a number of years where data indicates they have got better in this.. It's a bit like when first publishing deaths in hospitals. Journalist had FOI so better to do it yourself $(\operatorname{InT} 21)$.

Recently the MHISSC has been looking at emergency data for MH. One jurisdiction has been discussing and presenting on what we classify with respect to mental health presentations in 
emergency departments. These kinds of presentations do have an impact on potential future directions, it can act as a mechanism for driving possibilities for improvement. Of course our discussions are dedicated to experience of states/territories with respect to the data and this can promote shared learning (InT 9).

I would say there are plenty of examples of collaborative efforts across states/territories as a consequence of being on committees and that these have increased over the last 5 years. It used to be the case that the national committees were to serve the national data set and getting that to work "but the states/territories have richer data and it's been possible to pool that data together at times for own initiatives. For example the case of national restraint. This has been a strong policy position from the SQPSC over the last 5 years but there was nothing in the national minimum data set to bring this together. The development of data in this area has been a consequence of a group of states getting together and agreeing to share information. Eg. the SECREST (data on seclusion on restraint). Now the MHISSC is moving towards making seclusion a DSS - a voluntarily collected data set (Int 14).

I think the infrastructure to make decisions actually has a pretty good track record. The changes we now have were inconceivable when compared to the 1980s. You couldn't make a national report of anything back then (Int 3).

I think it's true to say that everyone involved learns through these processes both with respect to other jurisdictions but also in terms of what is meaningful to particular data items. It does involve people with specific expertise that is then shared in the context of the committee proceedings. For example QLD has taken the lead in perinatal registries. It is possible to get a range of things on the agenda. It is a learning process with respect to the committee process but it is up to the different jurisdictions as to what they then do (Int 3).

Every 18 months there is a restructuring in health, though that national mental health plans now match with state plans is a most significant change (Int 20). 
There have been a number of interesting monumental problems for example where different jurisdictions have thought they were measuring consistently but then they discover later that this has not been the case. You saw this particularly with the coming of the NHPA which measures at hospital unit level as opposed to jurisdictional level - this made differences more visible (InT 3).

However, this State respondent noted some important developments in recent years. He stated,

With Commonwealth cashing out to PHNs and joint planning, we are seeing a great step forward. Previous regimes just came over the top of us....they didn't target people we were interested in at all...It wasn't sensible or equitable way. They need to look at State's existing investment. It's no way to do business, it's no way to just come over the top of us. (Int 20)

(Agreement on mental health committee - AS) has wooed and waned at different times and certain jurisdictions, particular newcomers to the national committee system, hold particular views for a while but eventually tend to come to common views about the field (InT 4).

There is some ambiguity in all these processes in that $C / W$ has central role in policy settings/funding but in mental health $C / W$ increasingly provider eg. GPs mental health plans, the allied professional \& psychologist initiative but $C / W$ as purchaser and provider has not come to table in terms of measurement. States/territories have been building their transparency and taking responsibility in that way but who drives these for $C / W$ (InT 14)

\subsection{Findings and discussion}

This report has summarized conceptual discussions of learning in the scholarly literature, as well as presented initial findings from a first round of interviews of Australian policy elites working across Australia's intergovernmental health machinary. These interviews are the first of their kind to examine intergovernmental processes in Australia's Federal Health system. The empirical findings can now be examined against the background of the initial discussion of scholarly concepts about mutual learning and whether and how this occurs. This is a preliminary study and the discussion here is to guide future conceptual development and inform the collection of further data. 


\section{On identifying mutual learning}

The key focus has been upon identifying learning as mutual adjustment in perceptions about performance and related adjustments in systems and action. According to the accounts of respondents, a first finding is that there are various claims that mutual learning through intergovernmental exchanges about performance has occurred. At least, as noted in the previous section 7.4 about developing trust and mutual learning, there were numerous references to claims of learning from intergovernmental exchanges by policy officials involved in these processes. Their examples included specific changes in belief and behavior to given performance objectives such as reducing voluntary restraint in the mental health sector, decreasing emergency waiting times in the somatic health sector, and more broadly engaging about a range of diverse performance measures that were collected or measured differently. In both sectors there has been, or is about to be, major changes introduced to their national performance measurement regimes, which it has been argued is motivated by ongoing experience with these systems. Of course, findings drawn from interview respondents about claims of learning must be considered cautiously. It has long been recognized that elite actors generally over estimate their successes, in particular when it comes to claims about learning. The findings here can however be used to undertake further examination about the acclaimed performance achievements and other data such as documentary sources and information (eg. evaluations) from other respondents can be used to further interrogate these findings.

It is for now noteworthy that the respondents interviewed were often long standing members of committees and made their claims about learning from their personal assessments of how performance measurement regimes were developed and discussed in previous decades. The claims about learning here presented are to be used for further analysis and investigation. A second, more precise finding, is that it is apparent that (some) State's themselves have been proactive in developing their own performance measurement systems, particularly in somatic/hospital care and that these systems are more sophisticated than the national data set used primarily for reporting. Thirdly, it is apparent that there are a range of different performance measurement sets including the national data set collections for public reporting, but also performance measures specific to intergovernmental agreements. It is not always the 
case that these data sets overlap. This requires further investigation in future research and some consideration when examining learning and then about and from what? Fifthly, it is clear that there are oscillations in experiences of mutual learning and that the same actors may identify experiences of learning and high trust with functional colleagues but also mistrust and disappointment with ambitions for the performance measurement regimes and learning.

A related caveat to claims of learning includes the recognition that learning and adjustment through intergovernmental processes tend to be very slow. Numerous respondents identified the consensus processes within the intergovernmental system as on the one hand conducive to learning, but on the other hand time consuming and incremental processes. This recognition of incremental change is unsurprising to scholars of learning but distinct from accounts of Australia's political administrative processes which tend to emphasize the winner take all dimensions of the majoritarian Westminster system. Furthermore, the findings of consensus orientation and the accounts of exchanges that take place in these processes are distinctive from more public political styles of antagonism in Australian political/policy processes.

\section{On quality of interaction}

Some more general observations can be made about the features of cross jurisdictional interaction in Australia's intergovernmental system. It is noteworthy that a number of these features do, at some points in time, correspond to attributes associated with learning in the scholarly literature. The first of these attributes is the generally small and well-connected community of actors that participate in these processes. A key finding from this research has been to confirm the 'small world' or rather stable group of policy officials in the federal health and mental health system. More specifically, the findings here indicate that ongoing interaction among actors across the jurisdiction is most clearly established among officials in the lower level committees and then among State actors. The research revealed that Commonwealth participants at this level have become more turbulent over time, with Commonwealth representatives regularly changing or shifts away from past ongoing contacts (in mental health) within the Commonwealth Department of Health. Significantly, State respondents expressed 
disappointment at this development.

It also became apparent that the intergovernmental processes were actually quite formally structured although not per se in a way that enabled or required peer review of members different performance experiences. Nevertheless, some respondents did identify the presence of robust dialogue and authentic sharing of problems and failures. Many of the examples of ongoing inquiry identified by respondents seemed to remain at the stage of: what are you doing or why is it different rather than how can you or we do this better and when or how will this be checked/assessed? Noteworthy from the interview data was the nature of exchange which did on many occasions appear to correspond to ideas of fruitful conflict. Again, in contrast to the parliamentary mode of exchange in Australia, the committee system clearly hosted (at times and at certain levels of the hierarchy) an argumentative style that was more akin to inquiry and learning than strategic bargaining/coercion. Moreover, the members of the committee system frequently interact informally. Noteworthy with respect to relations between the formal commitment to performance and informal action were some references within services that seemed to indicate a different governing rationale than that of the intergovernmental committee system. This can in part be explained by the need of different kinds of performance measures at the level of the service provider but does not discount evidence that the relevance of performance measures to use and decision making in delivery organizations seemed to be disconnected or only becoming more connected in some instances.

Future research and consideration also needs to be given to the role of financial incentives in promoting learning and then how to conceptualize this learning. Clearly the findings in this study indicated that financial incentives were an important mechanism for attaining performance commitments from the States though these also interfered with other performance objectives. It is not a new finding to suggest that financial incentives are a significant lever in the Australian Federal Health system, but this study raises queries as to their long term effects and the importance of good design. The NEAT and NEST measures in hospital performance for example seem to be better characterized as forms of instrumental or political learning than mutual learning, though perhaps such arrangements could be used more artfully to pave the way for 
building trust and more effective performance initiatives.

It was also apparent that there may be important distinctions between interaction trajectories and processes in mental health vis a vis somatic health. Not least the bipartisan versus partisan character of these policy fields in political debates, but perhaps relatedly distinctions in the design trajectories and exchanges processes of their related committees. For example, it is evident that the national mental health performance measures have generally been developed by policy expert processes, though somatic/hospital measures have at times had greater influences from political decision makers. Furthermore, the mental health intergovernmental machinery is more clearly inclusive of greater plurality in knowledge than the somatic health/hospital machinery, where lay publics/sufferers/carers are incorporated on a number of the committees. It would be useful to examine more carefully the role that these different membership constellations of interaction processes have upon mutual learning about performance, and relatedly the postures of actors in the committee exchanges. To return to the conceptual discussion earlier in this report, one may wonder if socialization to more strategic interaction has been more prominent in the somatic health performance exchanges than mental health eg. as a consequence of nature of interaction and indeed history of conflict in the field.

Finally there were also numerous references to the barriers or rather interruptions to learning and decision making processes, in particular as a consequence of government change, input or veto of performance proposals. For example it was apparent that functional actors were more clearly committed to data sharing and exchange for learning than political actors who were more concerned about external appearances and approval. Another impediment to learning would appear to be the lack of willingness to share data about certain issues and at certain times and the lack of more general commonality in performance metrics. While Australia's national performance framework has arguably been consolidated since its initiation in the 1990s, it remains remarkable that there is not more extensive or common performance metrics across the health system. The apparent inability to develop common metrics or indeed share data more fully does suggest that there are significant trust issues in the relationships between Commonwealth and State policy actors in the realm of Australia's federal health system. While this is of great 
concern, it also indicates that significant advantage is likely to gained from improving the processes and interaction between State/Commonwealth officials in the intergovernmental realm.

\subsection{Future directions}

This study has presented preliminary findings regarding cross jurisdictional interaction in Australia's intergovernmental machinery. It has sought to group these findings together with existing understandings of routines of interaction deemed productive for learning in the scholarly literature. However, it has not been possible in the current research confines to triangulate this data with other research nor examine the potential relationship of learning at the micro level of individuals to changes at the meso or macro level or indeed the direction of change. Beyond, triangulating the existing data and claims about learning at the individual or intergovernmental level in this research, future research could seek to link such micro adjustments to changes at the level of performance regimes, and indeed examine the types of such adjustments and their direction as per Thelen \& Wolfgang's characterization of types of incremental change (Streek and Wolfgang 2005) (see section 4.0 this report).

Another refinement to the present analysis would be to develop or adopt a tidier conceptual framework of routines of interaction at the level of the intergovernmental committee/ Commonwealth agency actors. It was apparent from this study that habits of interaction sometimes vary, even in the same committee, depending on the performance indicator/issue being discussed and as a consequence of political/government changes and involvement. While the various factors identified in this study as contributing to learning were useful, their diversity seemed to work against the development of a more synthesized conceptual framework. One possible alternative is the adoption of the Grid Group Cultural theory framework presented below - which would be able to assess the cultural character of habits of interaction as derived from practices of performance exchange in a given social organization - that is in a field of actors defined by degree of common norms (group) and degree of formal rules (grid). Such a framework may be able to manage the diversity apparent in performance frameworks and how 
they are used/interacted about depending on issue or time frame - such as when a new government affects decision making processes or incentives. The GGCT framework, and how it might relate to national performance regimes, is presented in table 3 below

GGCT is an organizational theory that posits four cultural 'ways of life' that govern interactions, these include mutuality, but also hierarchy, competition and fatalism. These worldviews are derived from two basic dimensions of sociality including grid - the degree to which peoples' lives are circumscribed by rules, and group - the degree to which people are tied to one another as a collective. Crucially these ways of life refer to the importance of formal and informal features of social organization and how these shape interaction. They can be brokered together to different degrees in organizational arrangements for coordination and regulation across jurisdictional levels. The application of GGCT to institutional forums and regulatory agencies designing, collecting and overseeing hospital and mental health performance regimes is summarized below:

Table 1. Coordination of performance according to GGCT adapted from Heims 2016

\begin{tabular}{|c|c|c|}
\hline \multicolumn{3}{|c|}{ Group } \\
\hline \multirow{8}{*}{ 它 } & Fatalism & Hierarchy \\
\hline & Performance measures through top down & Performance measures through top down \\
\hline & ordering that is reluctantly & ordering that is accepted by lower level actors. \\
\hline & $\begin{array}{l}\text { endured/opportunistically evaded by } \\
\text { lower level actors. }\end{array}$ & \\
\hline & No Trust & $\underline{\text { Trust in rules }}$ \\
\hline & Competition & Mutualism \\
\hline & $\begin{array}{l}\text { Performance measures associated with } \\
\text { market mechanisms/incentives, rivalry or } \\
\text { individualistic bargaining. }\end{array}$ & $\begin{array}{l}\text { Performance measures through group } \\
\text { processes, mutual exchange and learning. }\end{array}$ \\
\hline & Thin Trust & Thick normative Trust \\
\hline
\end{tabular}

It is important to recognize that GGCT can be seen as presenting a set of social practices about ways of life- that is both action with values. Moreover, it can be used to derive and examine micro foundations of learning from performance measures that relate to different cultural contexts. A key research agenda would be to identify the mechanisms functioning in each way of life to re-produce those patterns of interaction. Moreover GGCT also incorporates a theory of change that can be studied over time, such as adjustments for learning. It may be used to examine and link organizational routines with higher level processes of institutional change. 


\section{References}

Ansell, C. \& Bartenberger, M. (2016). Varieties of experimentalism. Ecological Economics Vol. 130:61-73.

Ansell, C. (2011). Pragmatist Democracy. Evolutionary learning as public philosophy. Oxford: Oxford University Press.

Ansell, C. \& Gash, A. (2008). Collaborative Governance in theory and practice. Journal of Public Administration Research and Theory 18(4): 543-571.

Anderson, J. (2012). Health Policy as contested terrain in the Australian Federation In P. Kildea, A. Lynch \& G. Williams (eds.) Tomorrow's Federation. Reforming Australian Government. Riverwood: The Federation Press.

Blom-Hansen, J \& Brandsma, J. (2009). The EU Comitology System: Intergovernmental Bargain \& Deliberative Supranationalism. Journal of European Common Market Studies 47(4): 719-740.

Bohman, J. (1999). Democracy as Inquiry, Inquiry as Democratic: Pragmatism, Social Science and the Cognitive Division of labor. American Journal of Political Science 43(2):590-607.

Botterill, L. (2007). Managing Intergovernmental Relations in Australia. The case of agricultural policy cooperation. Australian Journal of Public Administration 66(2): 186-197.

Camic, C. (1986). The matter of habit. American Journal of Sociology 91(5): 1039-1087.

Checkel, J. (2007). International institutions and socialization in Europe. Oxford: OxfordUniversity Press.

Cohen, M. \& Sabel, C. (1997). Directly Deliberative Polyarchy. European Law Journal, 3(4): 313-342

Cohen, M. (2007). Reading Dewey: Reflections on the study of routine. Organization Studies 28(05):773-786.

Davies, C. (2007). Grounding governance in dialogue? Discourse, practice and the potential for a new organizational form in Britain. Public Administration 85 (1):47-67.

Dewey, John. (1927). The Public and its Problems. New York: Henry Holt \& Company.

Dewey, John. (1938). Logic. The theory of inquiry. New York: Henry Holt \& Company.

Dewey, John. (1939). Theory of valuation. Chicago: University of Chicago Press.

Feiock, R. \& Scholz, J. (eds.) (2010). Self-Organizing Federalism. Cambridge: Cambridge University Press. 
Gambetta, D. (1988). Can we Trust Trust? Trust making and breaking cooperative relationships. Oxford. Oxford University Press.

Gehring, T. \& Krapohl, S. (2005). Supranational regulatory agencies between independence and control: the EMEA and the authorization of pharmaceuticals in the European single market. Journal of European Public Policy14(2): 208-226.

Gehring, T. \& Oberthur, S. (2009). The causal mechanism of interactions between international institutions. European Journal of International Relations 15(1): 125-156.

Gehring, T. (2012). Deliberative regulation through European agencies and other network structures? In M.Busiouc, M. Groenleer \& J. Trondal (eds.), The Agency Phenomena in the European Union. Manchester: Manchester University Press, pp. 105-127.

Gillardi, F. \& Radaelli, C. (2012). Governance and Gearning in Levi-Faur, D. (ed.). The Oxford Handbook of Governance. Oxford: Oxford University Press. pp.155-169.

Gross, Neil. (2009). A Pragmatist Theory of Mechanisms. American Sociological Review 74, June: $358-379$.

Jacobs, A. \& Weaver, R. (2015). When policies undo themselves, self-undermining feedback as a source of policy change. Governance 28(4): 441-457.

Joerges, C. \& Neyer, J. (1997). Transforming strategic interaction into deliberative problemsolving: European comitology in the foodstuffs sector. Journal of European Public Policy 4(4):609-25.

May, P. (1992). Policy learning and Policy Failure. Journal of Public Policy 12(4): 331-354.

Meyer, J.W. \& Rowan, B. (1977). Institutionalized organizations. Formal structure as myth and ceremony. American Journal of Sociology, 83: 340-363.

Mitzsal, B. (1996). Trust in Modern Societies. Oxford: Oxford University Press.

Moynihan, D. (2008). The dynamics of performance management. Washington DC: Georgetown University Press.

Painter, M. (1998). Collaborative federalism: Economic reform in Australia in the 1990s. Cambridge: Cambridge University Press.

Rogers, M. (2009). Democracy, elites and power: John Dewey reconsidered. Contemporary Political Theory 8(1):68-89.

Sabel, C. (1993). Studied Trust: Building new forms of cooperation in a volatile economy. Human Relations 46(9):1133-1170. 
Sabel, C. (1994). Learning by monitoring: The institutions of economic development. In NJ. Smelser \& R, Swedborg. (eds.) The Handbook of Economic Sociology, Princeton University Press, Princeton.

Sabel, C. (2012). Dewey, democracy and democratic experimentalism. Contemporary Pragmatism 9(2): 35-55.

Sabel, C. \& Zeitlin, J. (2012). Experimentalist Governance in the European Union. Oxford: Oxford University Press.

Sennett, R. (2012). Together. The rituals, pleasures, and politics of cooperation. London: Penguin Books.

Streek, Wolfgang. \& Thelen, Kathleen. (2005). Beyond continuity. Institutional change in Advanced Political Economies. Oxford: Oxford University Press.

Zurn, M. \& Checkel, J. (2005). Getting socialized to build bridges. Constructivism and rationalism Europe and the Nation State. International Organization 59:1045-1079. 